\title{
La protección jurídica del derecho humano al medio ambiente sano en Uruguay
}

The Legal Protection of the Human Right to a Healthy Environment in Uruguay

\author{
Martina Brun Pereira \\ Universidad Católica del Uruguay \\ ORCID: 0000-0002-3183-3238 \\ Correos: martinabp.33@gmail.com
}

Recibido: 05/04/2021

Aceptado: 08/06/2021

\section{Resumen:}

El presente artículo tiene como propósito analizar la protección jurídica del derecho al medio ambiente en Uruguay para observar si dicho sistema responde a la regulación y los estándares desarrollados en el sistema regional. Para ello se analiza jurisprudencia nacional junto a diversos trámites parlamentarios que llevaron a la aprobación de normas referentes a la protección del derecho mencionado. El artículo reflexiona, en suma, respecto del tratamiento que ha tenido el derecho al medio ambiente en Uruguay, además de considerar algunos aspectos competenciales que significan los desafíos actuales de tal derecho. Entre las conclusiones se destaca que los estándares regionales constituyen directrices interpretativas que incentivan a países como Uruguay a adoptar actitudes jurídicas más eficaces para la protección del medio ambiente, y que, pese al amplio respaldo que posee el ordenamiento interno, este no se ha aplicado de forma significativa en el país.

Palabras clave: derecho ambiental; protección jurídica; sistema regional; sistema nacional uruguayo; derechos humanos.

\begin{abstract}
:
The purpose of this article is to analyze the legal protection of the right to the environment in Uruguay to observe whether this system responds to the regulations and standards developed in the regional system. To this end, it analyzes national jurisprudence together with various parliamentary proceedings that led to the approval of norms concerning the protection of the right. The article reflects, in short, on the treatment of the right to the environment in Uruguay, in addition to considering some aspects of jurisdiction that represent the current challenges of this right. Among the conclusions it is highlighted that the regional standards constitute interpretative guidelines that encourage countries like Uruguay to adopt more effective legal attitudes for the protection of the environment, and that, in spite of the wide support that the domestic law has, it has not been applied in a significant manner in the country.
\end{abstract}

Keywords: environmental rights; judicial protection; regional system; Uruguayan Nacional System; human rights. 


\section{Introducción}

Mitigando cualquier diferenciación que quite efectividad a los Derechos Económicos, Sociales y Culturales, categoría en la que se incluye al derecho al medio ambiente, corresponde entender a este como uno inherente a la personalidad humana, por lo cual su cumplimiento debe ser atendido y tutelado.

Hoy en día, la protección ambiental se ha convertido en un imperativo para todos quienes habitan este planeta. La ciencia demuestra la seriedad de las consecuencias derivadas de las vulneraciones al medio ambiente y su creciente afectación en los individuos, organismos y el planeta en sí. Los diversos mecanismos jurídicos internacionales y regionales, aunque demorados, están representando una oportunidad para documentar y presentar casos que evidencian afectaciones en materia ambiental (Calderón Gamboa, 2017, p. 103), los cuales pretenden ser empleados como directrices por parte de los Estados.

Es precisamente en función de ello el motivo de elección de este tema para el presente artículo. El derecho al medio ambiente no solo se debe tutelar a raíz de los perjuicios que puede producir su deterioro en el ser humano, sino que también se lo ha de proteger en atención al planeta en sí. De él es de donde extraemos la mayoría de los recursos, los cuales no son perpetuos por lo que tenemos el deber de preservar. No obstante, pareciera que, pese a la regulación jurídica de este derecho, aún no ha tenido suficiente trascendencia como debería.

El objetivo de este trabajo se concentra, en primer lugar, en determinar si la evolución en la protección jurídica del derecho al medio ambiente en el ámbito regional ha influido en la regulación jurídica de tal derecho en el ordenamiento interno de Uruguay. Luego, en segundo lugar, analizar los desafíos actuales que afronta el sistema uruguayo en materia de protección ambiental.

Para ello se comenzará ahondando brevemente en los antecedentes del derecho al medio ambiente en el plano internacional, para luego adentrar en las manifestaciones posteriores y la evolución en la regulación del derecho al medio ambiente sano en el sistema regional, además de referir a los estándares utilizados en la materia por dicho sistema. Posteriormente se tratará la evolución jurídica que ha tenido tal derecho en el ámbito nacional, observando si el sistema uruguayo responde a los estándares desarrollados en el sistema regional. Finalmente, se culminará haciendo alusión a los 
desafíos actuales que presenta el ordenamiento nacional de Uruguay en relación con la regulación jurídica de este derecho.

\section{Antecedentes: el despertar del derecho humano al medio ambiente}

Al final de la Segunda Guerra Mundial las principales potencias del mundo encontraron necesario el establecimiento de un orden y equilibrio que buscara asegurar el respeto por los Derechos Humanos de los individuos promoviendo la paz y la seguridad internacional. Es a partir de 1948 con la adopción de las Declaraciones Americana y Universal de Derechos Humanos, que se inicia un proceso dinámico de desarrollo de la protección internacional de los Derechos Humanos con incidencia paulatina en el derecho interno de cada Estado (Blengio, 2012).

En los primeros instrumentos referidos enteramente a los Derechos Humanos se omitió la alusión a los derechos medioambientales como una especie indisociable. La Carta Africana sobre los Derechos Humanos y de los Pueblos, adoptada en 1981, constituye el primer instrumento internacional (Cerqueira, 2020, p.3) en reconocer el derecho a un ambiente satisfactorio, dado a que si bien existieron documentos que antecedieron a esta Carta, habían sido ineficientes. En el marco de dicho proceso y en lo que respecta al tema ambiental, la concientización en relación con la existencia de los recursos limitados de la Tierra y la falta de fronteras para el ambiente, así como el fenómeno de la internacionalización de los daños ambientales y sus irreparables consecuencias, ha generado en forma progresiva un vertiginoso desarrollo. Dicha preocupación y, en consecuencia, el desarrollo de la normativa internacional en relación con la protección del medio ambiente ha dado lugar al surgimiento de una rama denominada Derecho Ambiental. El trabajo en esta área es de especial interés para su prevención, protección y garantía, cuya observancia resulta vital para el devenir humano.

\section{Evolución en la regulación del derecho al medio ambiente sano}

\section{Sistema regional interamericano}

En el sistema regional, en un principio, en ningún artículo se nombra al derecho del medio ambiente como una garantía a proteger; sin embargo, esto fue parcialmente suplido en 1988, con la adopción de un Protocolo Adicional a la Convención Americana sobre Derechos Humanos en materia de Derechos Económicos, Sociales y Culturales, también conocido como Protocolo de San Salvador. El Protocolo entró en vigor en 
noviembre de 1999 significando un avance en lo que respecta a la protección jurídica del derecho al medio ambiente sano al proclamar al mismo como un derecho humano, por lo que dicha protección se convirtió en una garantía fundamental. Este instrumento, en su artículo 11 establece: " 1 . Toda persona tiene derecho a vivir en un medio ambiente sano y a contar con servicios públicos básicos. 2. Los Estados partes promoverán la protección, preservación y mejoramiento del medio ambiente".

De esta manera, el Protocolo de San Salvador establece la protección del medio ambiente directamente, sin recurrir a su defensa indirecta, estableciéndose una clara diferencia con otros sistemas regionales, tales como el Sistema Europeo de Derechos Humanos. No obstante, es relevante tener presente que a pesar de ser el Protocolo de San Salvador un instrumento integrante del sistema, este no ha sido ratificado por todos los Estados Americanos, por lo tanto, las garantías consagradas no son exigibles a la totalidad de países del continente. En este sentido, también corresponde destacar que la protección directa del entorno valdrá solo para las alegaciones que se entablen ante la Comisión Interamericana de Derechos Humanos.

Por otra parte, y en directa relación con la protección y respeto del entorno natural, se encuentra el Proyecto de Declaración Americana sobre los Derechos de las Poblaciones Indígenas, aprobado por la Convención Interamericana de Derechos Humanos el 26 de febrero de 1997. Este instrumento reconoce en su preámbulo el respeto que los pueblos originarios tienen al medio ambiente y la relación especial que mantienen con él. Además, en su artículo XIII señala que las poblaciones indígenas tienen derecho a la protección del medio ambiente y establece una serie de garantías relacionadas con la efectiva implementación de dicho derecho. Así, cobra relevancia para el derecho ambiental la herencia cultural indígena existente en el continente americano.

En este mismo sentido, y refiriéndonos a la normativa que regula la protección jurídica del derecho al medio ambiente en el sistema regional, corresponde aludir a algunos de los compromisos intergubernamentales expuestos en resoluciones de los órganos políticos de la OEA. En este punto se recoge a continuación el repaso que hace Daniel Cerqueira (2020) en su trabajo El derecho a un medio ambiente sano en el marco normativo y jurisprudencia del Sistema Interamericano de Derechos Humanos.

Uno de los compromisos intergubernamentales más relevantes se encuentra en la Carta Democrática Interamericana, de 2001, cuyo preámbulo establece que "un medio ambiente sano es indispensable para el desarrollo integral del ser humano, lo que 
contribuye a la democracia y la estabilidad política". A su vez, el artículo 15 refiere a lo significativa que es la democracia representativa para la preservación y adecuado manejo del medio ambiente y subraya la necesidad de adoptar políticas y estrategias de protección para respetar así los diversos tratados y convenciones (Cerqueira, 2020, p. 6).

Poco después, en ese mismo año se emite la primera resolución referente a Derechos Humanos y Medio Ambiente por parte de la Asamblea General de la OEA. Esta es renovada en forma periódica a partir de la correlación entre el goce de los derechos humanos y la preservación del medio ambiente y el desarrollo sostenible. Es de interés señalar que en el marco de estos documentos viene siendo reiterada desde el año 2008 la resolución titulada "Derechos Humanos y Cambio Climático en las Américas", que trata los compromisos interestatales definidos en conferencias especializadas y declaraciones en el ámbito de la ONU sobre la materia (Cerqueira, 2020, p. 6).

Continuando con los distintos instrumentos que regulan la protección jurídica del derecho competente, la Carta Social de las Américas — aprobada por la Asamblea General de la OEA en el 2012 - reconoce el vínculo entre un medio ambiente sano y el desarrollo integral (Cerqueira, 2020, p. 6).

El artículo 17 de este documento establece el compromiso de los Estados parte de "promover formas de vida sana y de fortalecer su capacidad para prevenir, detectar y responder a enfermedades crónicas no contagiosas, enfermedades infecciosas actuales y emergentes y a los problemas de salud relacionados con el medio ambiente", mientras que el artículo 22 subraya el compromiso de mejorar la cooperación regional en prevención, respuesta, mitigación del impacto y evaluación de los desastres, así como de enfrentar los impactos de la variabilidad climática y los efectos adversos del cambio climático (Carta Social de las Américas, 4 de junio de 2012).

En 2007 la Asamblea General de la OEA creó un grupo de trabajo (GT) encargado de definir los indicadores de progreso de los derechos económicos, sociales, culturales y ambientales (DESCA), que deben ser reportados por los Estados Partes del Protocolo de San Salvador. En la Asamblea General de 2014 se fijó un mecanismo de seguimiento a la implementación del Protocolo en lo referente a la materia ambiental.

Para ello la OEA estableció ciertos parámetros para la evaluación, los cuales versan en función de: las condiciones atmosféricas; la calidad y suficiencia de las fuentes hídricas; la calidad del aire; la calidad del suelo; la biodiversidad; la producción de 
residuos contaminantes y manejo de estos; los recursos energéticos, y el estado de los recursos forestales (Cerqueira, 2020, p. 5).

Este grupo de trabajo se ha referido a los deberes de los Estados en torno al artículo 11 del Protocolo: garantizar un medio ambiente sano sin discriminación alguna; ofrecer servicios públicos esenciales a todas las personas y; promover la protección, preservación y mejoramiento del medio ambiente. El GT estableció los criterios de disponibilidad, accesibilidad, sostenibilidad, aceptabilidad y adaptabilidad, comunes a otros DESCA, como orientadores de las referidas obligaciones. Si bien el monitoreo constituye una herramienta importante de medición del goce de los DESCA, la ausencia de un marco institucional provisto de amplias facultades de monitoreo y la falta de disposiciones específicas traslada a los órganos del Sistema Interamericano de Derechos Humanos (SIDH) la función de establecer estándares sobre el derecho a un medio ambiente sano y otros derechos conexos (Cerqueira, 2020, p. 5)

Posteriormente, la Declaración Americana sobre los Derechos de los Pueblos Indígenas, de 2016, vuelve a referir a la protección jurídica del medio ambiente. Su artículo 19 establece que dichos pueblos tienen derecho a vivir en conformidad con la naturaleza y un ambiente sano, seguro y sustentable, en condiciones propicias para el pleno goce de otros derechos conexos.

No obstante, la relación entre medio ambiente y derechos fundamentales puede ser aún más estrecha a futuro, ya que los objetivos de desarrollo sostenible redactados en el año 2015 para el año 2030 expresan, en lo que respecta al medio ambiente, que el objetivo se centrará en la creación de capacidad para el desarrollo, fortalecimiento y efectividad de las leyes, políticas e instituciones en materia ambiental de manera que generen responsabilidad, transparencia e inclusión en apoyo del desarrollo sostenible, los derechos humanos y la paz en las Américas.

\section{Estándares desarrollados en el ámbito regional interamericano}

Abordado el desarrollo de la protección jurídica del derecho al medio ambiente en el sistema regional, corresponde mencionar los estándares que se han desprendido de la ecologización de los órganos de dicho sistema. En este sentido, la Comisión Interamericana de Derechos Humanos (CIDH) y la Corte Interamericana de Derechos Humanos (Corte IDH) poseen una variedad de pronunciamientos que, si bien no examinan específicamente el derecho a un medio ambiente sano, establecen algunos 
parámetros de actuación estatal dirigidos a proteger y preservar el ambiente por medio de la protección de otros derechos humanos, comprendiéndolos a través de una visión integral.

Tales pronunciamientos se han dado sobre todo en casos vinculados al derecho de propiedad colectiva - artículos 21 de la Convención y 23 de la Declaración Americanade los pueblos indígenas y tribales. Pues, podría afirmarse que en materia ambiental existe cierta inclinación jurisprudencial dirigida a la resolución de casos vinculados con dichas poblaciones, donde en función de ello se evidencian posiciones que, "inevitablemente, se desarrollaron a partir del análisis de casos que difícilmente se pueden abordar de manera rutinaria en un sistema de protección que no se inserta en las especificidades regionales de las Américas” (De Olivera Mazzuoli y De Faria Moreira, 2015, p. 49).

\section{Casos de derechos humanos vinculados al medio ambiente}

Como bien se mencionó anteriormente, durante los múltiples casos ante la Corte IDH, esta ha dado uso del corpus juris internacional en materia medioambiental para interpretar situaciones concretas, a través de la integración de diversas áreas del derecho, brindando, así, distintas esferas de protección. Por ejemplo, el caso Kaliña y Lokono refleja con claridad el reconocimiento de la complementariedad entre los derechos medioambientales y el de los Pueblos Indígenas y Tribales al expresar que la Corte encuentra importante referir a la necesidad de compatibilizar la tutela de las áreas protegidas con el adecuado uso y goce de los territorios tradicionales de la población indígena (Corte IDH. Caso Pueblos Kaliña Y Lokono vs. Surinam, 2015, párr. 173).

De este modo, la Corte estima que un área protegida consiste no solamente en la dimensión biológica, sino también en la sociocultural y que, por tanto, incorpora un enfoque interdisciplinario y participativo (Secretaría del Convenio sobre la Diversidad Biológica, 2004). En este sentido, los pueblos indígenas, por lo general, pueden desempeñar un rol relevante en la conservación de la naturaleza (Declaración de Río Sobre el Medioambiente y el Desarrollo, 2020, principio 22), dado que ciertos usos tradicionales conllevan prácticas de sustentabilidad y se consideran fundamentales para la eficacia de las estrategias de conservación (WWF Internacional, 2008).

Por ello, el respeto de los derechos de los pueblos indígenas puede repercutir positivamente en la conservación del medioambiente (Corte IDH. Caso Pueblo Saramaka Vs. Surinam., 2008, párr. 40 y 41; Caso Comunidad Indígena Sawhoyamaxa vs. 
Paraguay. 2006, párr. 119 y 120). Así, el derecho de los pueblos indígenas y las normas internacionales de medio ambiente deben comprenderse como derechos complementarios y no excluyentes (Comisión Mundial de Áreas Protegidas y WWF Internacional, 2001; Corte IDH. Caso Comunidad Indígena Yakye Axa vs. Paraguay, 2005, párr. 161 y 162).

Asimismo, a través de los casos Saramaka, Sarayaku y Kaliña y Lokono, se han expuesto importantes estándares sobre los estudios de impacto ambiental y social (EIAS) los cuales han arrojado recomendaciones, que remarcan su relevancia, a la luz de los desarrollos del derecho ambiental.

En lo que respecta a estos últimos, la Corte IDH ha señalado que son útiles para estimar el posible daño o impacto que un proyecto de desarrollo y/o inversión puede tener sobre la propiedad y comunidad ambiental. El objetivo de ello no es meramente tener alguna medida objetiva del posible impacto sobre el medio ambiente y las personas, sino también garantizar que los miembros de la comunidad tengan conocimiento de los posibles riesgos, incluidos los peligros ambientales y de salubridad, para que puedan evaluar si aceptan el plan de desarrollo o inversión propuesto, de manera voluntaria y con conocimiento (Corte IDH. Caso Pueblo Saramaka vs. Surinam, 2008, párr. 40 y 41 y Corte IDH. Caso Pueblo indígena Kichwa de Sarayaku vs. Ecuador, 2012, párr. 205). El nivel de impacto permitido no puede negar la capacidad de los miembros de los pueblos indígenas y tribales a su propia supervivencia (Corte IDH. Caso Pueblo Saramaka Vs. Surinam, 2008, párr. 42).

En este marco de sentencias del sistema interamericano referentes al medio ambiente, corresponde señalar el caso de la asociación Lhaka Honhat vs. Argentina, el cual marcó un hito en lo que respecta a la justiciabilidad directa de los DESCA en la Corte IDH. En este aspecto, la Corte IDH destaca la interdependencia entre el derecho a un medio ambiente sano -incluido por el artículo 26 de la Convención Americana sobre Derechos Humanos (CADH) - y los demás derechos humanos; donde expresa que los DESCA son derechos independientes y autónomos, lo que implica que no hay motivos para hacer depender el análisis de la violación de los DESCA de otro derecho de la CADH o de otros instrumentos sobre los cuales la Corte IDH tenga competencia (Corte IDH. Caso Comunidades indígenas miembros de la Asociación Lhaka Honhat [Nuestra Tierra] vs. Argentina, 2020, párr. 42 y 244).

Mediante estas sentencias también se observa la inclusión de la responsabilidad de otros actores no estatales - como las empresas- en el análisis de los daños 
ocasionados al medio ambiente, sin perjuicio de que la responsabilidad internacional en los derechos humanos persiste en el Estado ya que este es uno de sus deberes de garantía, a través de la regulación, supervisión y fiscalización en la materia.

Por otra parte, lo concerniente a otras materias no indígenas permite vislumbrar la relevancia de la utilización de diversos derechos convencionales para la protección del medio ambiente, tales como los derechos de participación política. También el derecho al acceso a la información en el caso Claude Reyes y otros vs. Chile, donde la Corte observó, entre otras disposiciones, las que garantizan el acceso a la información en cuestiones de medio ambiente. Analizó la Declaración de Río sobre el Medio Ambiente y el Desarrollo y encontró que, al no recibir la información solicitada ni una contestación motivada sobre las restricciones a su derecho al acceso a información bajo el control del Estado, las víctimas vieron afectada la posibilidad de realizar un control social de la gestión pública, lo que derivó en una violación del derecho a la información, consagrado en el artículo 13 de la CADH (Corte IDH. Caso Claude Reyes y otros vs. Chile. 2006, párr. 81; Declaración de Río sobre el Medio Ambiente y el Desarrollo, 1992, Principio 10).

Bajo este criterio la Corte IDH también utilizó el derecho a la vida digna o a la integridad personal y vida privada, por lo que se resalta la importancia de la protección, preservación y mejoramiento del medio ambiente contenido en el artículo 11 del Protocolo Adicional a la Convención Americana sobre Derechos Económicos, Sociales y Culturales, como un derecho humano esencial relacionado con el derecho a la vida digna precedente del artículo 4 de la Convención y sobre todo con la protección especial que requieren los miembros de las comunidades indígenas dado el deber general de garantía inmerso en el artículo 1.1 y, el deber de desarrollo progresivo contenido en el artículo 26 (Corte IDH. Caso Comunidad indígena Yakye Axa vs. Paraguay, 2006; Corte IDH. Caso Comunidad Indígena Xákmok Kásek vs. Paraguay, 2010, párr. 187; Corte IDH. Caso Pueblos Kaliña y Lokono vs. Surinam, 2015, párr. 172).

Cabe destacar que además de las directrices difundidas mediante sentencias de la Corte IDH existen pronunciamientos de la CIDH a través de sus facultades de monitoreo y promoción, en los cuales se han desarrollado y reafirmado los estándares anteriormente mencionados, por lo que a continuación nombraré alguno de ellos.

En este sentido, los informes temáticos han sido muy precisos en el desarrollo de obligaciones estatales referentes a prevenir, mitigar y garantizar derechos vulnerados por el manejo indebido de recursos naturales. 
Dentro de los distintos informes que enmarcan antecedentes relevantes acerca del derecho ambiental, es notable destacar tres de ellos que se mencionan a continuación.

(i) El informe Pueblos indígenas, comunidades afrodescendientes y recursos naturales: protección de derechos humanos en el contexto de actividades de extracción, explotación y desarrollo (Comisión Interamericana de Derechos Humanos, 2015). Trata conceptos clave para el entendimiento de la tensión entre actividades extractivas y la protección del medio ambiente, tales como ecosistema, biodiversidad, seguridad alimentaria y remediación ambiental.

(ii) El informe Situación de los derechos humanos de los pueblos indígenas y tribales de la Panamazonía (Comisión Interamericana de Derechos Humanos, 2019a) que comprende situaciones de afectación al medio ambiente, con las particularidades de la región amazónica. Constituye un análisis de variados fenómenos, tales como el cambio climático, y conceptos como tierra y territorio, a partir de su interrelación con la cosmovisión e identidad cultural de los pueblos indígenas.

(iii) El informe Empresas y Derechos Humanos: Estándares Interamericanos (Comisión Interamericana de Derechos Humanos, 2019b) contempla un apartado específico sobre el derecho a un ambiente sano que ratifica la estrecha relación entre derechos humanos, desarrollo sostenible y medio ambiente. Apunta a que las acciones reglamentarias y precautorias en la materia no solo han de ser adoptadas por parte del Estado, sino también por parte de los distintos entes y personas que forman parte del planeta (Cerqueira, 2020, pp. 19-21).

\section{Opinión consultiva 23/17 de la Corte Interamericana de Derechos Humanos}

En la misma línea de difusión de estándares por parte del sistema interamericano en materia de medio ambiente, es de interés señalar la opinión consultiva 23/17 a través de la cual la Corte IDH abordó el derecho al medio ambiente sano y otros derechos conexos. El documento fue solicitado por el Estado de Colombia y preguntó al tribunal interamericano: ¿cuál es el ámbito de aplicación de las obligaciones estatales relacionadas con la protección del medio ambiente que surgen de la $\mathrm{CADH}$ ? y, ¿cuáles son las obligaciones de los Estados en materia del medio ambiente, en el marco de la protección 
y garantía de los derechos a la vida y a la integridad personal consagrados en la CADH? (Cerqueira, 2020, p. 22).

A partir de los interrogantes la Corte IDH aborda el contenido del derecho al medio ambiente sano y otros derechos comúnmente vulnerados por la degradación del medio ambiente. Además, se aclara sobre el alcance del término jurisdicción en la Convención Americana, porque en reiteradas ocasiones los hechos que suceden en un Estado tienen efectos y vulneran derechos de personas ubicadas en el territorio de otros Estados. En relación con el derecho a un medio ambiente sano, la opinión consultiva subraya que, en su dimensión colectiva, tal derecho constituye un interés universal, vinculado tanto a las generaciones presentes como a las futuras (Cerqueira. 2020, p.22).

Ahora bien, el derecho al medio ambiente sano posee también una dimensión individual, ya que su vulneración puede repercutir de forma directa o indirecta sobre las personas por su relación con otros derechos como a la salud, la integridad personal o incluso a la vida. De este modo, la degradación del medio ambiente puede ocasionar daños irreparables en las personas, motivo por el que un medio ambiente sano es un derecho fundamental para la humanidad (Corte IDH, 2017, OC-23/17, párr. 59).

En los párrafos que siguen se recogerá lo expresado por Cerqueira (2020) respecto a la opinión consultiva 23/17. Este instrumento refiere al medio ambiente sano como un derecho autónomo y justiciable en el marco del artículo 26 de la $\mathrm{CADH}$, así como también corrobora el cambio jurisprudencial ocurrido en el año 2017 a partir del caso Lagos del Campo vs. Perú, sobre la aptitud de los órganos del SIDH para proclamar la vulneración directa de derechos protegidos en la referida disposición convencional (p. 22).

Además de ello, la opinión consultiva expresa que la violación de este derecho no implica necesariamente efectos negativos para un individuo en concreto. Concretamente, la Corte resalta que el citado derecho protege los componentes del medio ambiente, así como también los intereses jurídicos en sí mismos, aún en ausencia de evidencia y/o certeza acerca del riesgo a las personas. Se trata de tutelar la naturaleza y el medio ambiente no solamente por su conexidad con una utilidad para el ser humano o por los efectos que su degradación podría causar en otros derechos de las personas, sino por su relevancia para los demás organismos vivos con quienes se comparte el planeta, también dignos de protección en sí mismos (OC-23/17 citado en Cerqueira, 2020, p. 23).

La opinión consultiva intensifica el nexo de interdependencia e indivisibilidad entre la protección del medio ambiente y los derechos humanos, lo que resalta que los 
perjuicios ambientales pueden vulnerar todos los derechos fundamentales, pues, el pleno disfrute de tales derechos requiere de un medio adecuado.

De la misma forma que en los informes temáticos de la CIDH comentados en las anteriores líneas, la Corte IDH en este documento examina la especial situación de vulnerabilidad de algunas poblaciones frente a los daños ambientales, puntualizando los compromisos estatales de prevenir la vulneración de derechos y de garantía de personas que viven en estado de pobreza, pueblos indígenas y personas con discapacidad. Asimismo, incluye en esta esfera las comunidades que dependen de los recursos naturales, cuya vulnerabilidad consiste en una relación de índole económico o de supervivencia relacionada a ciertos recursos naturales (Cerqueira, 2020, pp. 23-24).

Por otra parte, la opinión consultiva entabla una serie de reglas respecto a la atribución de responsabilidad estatal frente a actos de particulares, donde se incluye bajo la esfera de responsabilidad, a países de origen de empresas que consuman daños al medio ambiente en el extranjero. El instrumento también abarca obligaciones específicas de carácter ambiental respecto a actores privados, al trazar parámetros de actuación estatal en cumplimiento del deber de prevención y garantía correspondiente a daños ambientales transfronterizos (Cerqueira, 2020, p. 24).

En el marco de este documento se resalta, además, la incorporación de dos principios esenciales del Derecho Internacional Ambiental, los principios de precaución y prevención a daños ambientales. En lo que refiere al primer principio, los Estados deben proceder cuando hay indicios de que cierta actividad pueda resultar en daños irreversibles al medio ambiente, aun cuando haya ausencia de certeza científica. Respecto al principio de prevención, este dispone el deber de regular, supervisar y fiscalizar actividades potencialmente dañinas al medio ambiente. Para efectuar este último principio se han de realizar estudios de impacto ambiental previo a la autorización de tales actividades, entablar un plan de contingencia en casos de daños y, moderar los efectos causados por la degradación ambiental. Adicionalmente, la opinión consultiva puntualizó las acciones que los Estados deben realizar en cumplimiento de su obligación de cooperación para la protección contra daños al medio ambiente. Sobre esta línea esclareció el contenido del derecho de acceso a la información, de participación pública en la toma de políticas y decisiones que pueden afectar el medio ambiente. Finalmente, la Corte IDH explicita el deber de los Estados de disponer de mecanismos apropiados de acceso a la justicia para la tutela del medio ambiente (Cerqueira, 2020, p. 24). 
Así, la OC-23/17 es esencial en materia medioambiental ya que sistematiza los estándares regionales que han de consagrar los Estados a fin de respetar, garantizar y prevenir daños ambientales.

\section{Sistema nacional uruguayo}

Desde 1934, la Constitución uruguaya en su artículo 72 establece que los derechos, deberes y garantías enumerados en las Secciones I y II no excluye a los otros que son inherentes a la personalidad humana. Así, cuando en los años 60 y 70 se comienzan a reconocer, en el plano internacional y regional, la protección ambiental y el desarrollo sostenible como deber del Estado, estos se integran al Derecho Constitucional uruguayo (Risso, 2005, pág. 772).

Señala Gorosito (2017):

Las Resoluciones de la Organización de las Naciones Unidas y las Declaraciones tanto de la Asamblea General de las Naciones Unidas como de las Conferencias Mundiales que en su sistema se han producido, en cuanto los textos refieran o establezca derechos, deberes y garantías en la materia ambiental que es inherente a la personalidad humana y reconocida como de jus cogens universal, son la constatación clara de esas ideas dominantes, de esa convicción colectiva universal, que ingresa de modo indubitable en la materia de los derechos, deberes y garantías fundamentales, tanto en sus aspectos individuales como colectivos, y que se encuadran de manera natural en el discurso jurídicamente vinculante de los Derechos Humanos (p. 126).

El autor destaca el caso particular de las Declaraciones de Estocolmo y Río, que exhiben "en la casi totalidad de los principios enunciados, la formulación y reconocimiento de derechos, deberes y garantías inherentes a la personalidad humana y que lejos de afectar o disminuir las protecciones conferidas por la Carta, las consolidan y reafirman" (p. 127).

El Principio 1 de la Declaración de Estocolmo y el principio 1 de la Declaración de Río, por ejemplo, convergen en expresar que el hombre tiene derecho a vivir y disfrutar de condiciones de vida adecuadas, en un medio ambiente propicio, de forma que le permita llevar una vida digna, por lo cual, el hombre tiene la obligación de proteger, lo cual constituye el centro de las preocupaciones relacionadas con el desarrollo sostenible. 
Lo mismo puede afirmarse respecto las regulaciones de contenido garantista y planificadoras de recursos naturales, que bajo la forma de principios sucesivamente se enuncian en ambas declaraciones, imponiendo deberes fundamentales a personas y organizaciones políticas. Sin perjuicio de ello, como se mencionó en el apartado anterior, el artículo 11 del Protocolo de San Salvador consagra que toda persona tiene derecho a vivir en un medio ambiente propicio y contar con los recursos esenciales. Esto lleva a que tras su aprobación con la Ley uruguaya N. ${ }^{\circ} 16.519$ de 1994 se entienda que esta norma - cubierta por el ámbito material de los otros derechos inherentes a la personalidad humana no enumerados - tiene rango constitucional (Gorosito, 2017, p. 127).

En el año 1997 se reformó la Constitución de Uruguay y se incluyó, por primera vez, un artículo relacionado directamente con el tema medio ambiente lo cual significó un gran avance ya que, si bien existían organismos en la materia desde 1971- a partir de la creación de Instituto Nacional para la Preservación del Medio Ambiente (INPMA) por Ley $\mathrm{N}^{\circ}$ 14.053- hasta el momento no había una regulación jurídica en forma expresa.

El artículo 47 de la Constitución establece:

La protección del medio ambiente es de interés general. Las personas deberán abstenerse de cualquier acto que cause depredación, destrucción o contaminación graves al medio ambiente. La ley reglamentará esta disposición y podrá prever sanciones para los transgresores.

Sin embargo, ese derecho no fue explicitado por el Constituyente con un texto asertivo de reconocimiento, sino que es en otro nivel jerárquico —el cual será abordado en los siguientes párrafos- que el Sistema Jurídico Ambiental uruguayo, explícito la consagración del derecho al medio ambiente: Ley N. ${ }^{\circ} 17.283$.

Los principios consensuados universalmente que se han proyectado en el derecho convencional y consuetudinario internacional han significado el contenido mismo de la protección ambiental, concepto clave del art. 47 de la Constitución. Este artículo ha constitucionalizado, por aproximaciones sucesivas, la materia de protección ambiental. A través de él es dable discernir dos momentos sucesivos en visión cronológica.

En la Reforma de 1997 se constitucionaliza la materia al incorporar la protección ambiental al rango constitucional normativo, lo que trajo consigo la incorporación del desarrollo sostenible como valor o meta valor. La protección ambiental se asume así en un nivel jerárquico superior al del interés general que puede calificar el legislador. Este 
interés general, resalta Gorosito (2017) “en cuanto tiene como finalidad la protección del ambiente como bien jurídico global o mundial, se inserta en la regulación universal de jus cogens, transformándose en otro puente que interrelaciona, el Derecho Internacional y el Derecho Nacional, como ocurre también con el artículo 72 de la Constitución” (p. 129).

A partir de lo expuesto, los avances regulatorios de fuente internacional se incorporan a la Carta de Uruguay en forma más directa, en cuanto dan contenido a los conceptos de medio ambiente, protección ambiental o interés general (Iglesias, 2020, pp. 141-143; y Valla, 2016).

En el ámbito de la protección ambiental, corresponde al Poder Ejecutivo la fijación de las políticas nacionales, que dentro de cuyo conjunto orgánico según lo dispone la Ley 16.112 que crea el Ministerio de Vivienda, Ordenamiento Territorial y Medio Ambiente, tal ministerio es el competente en la formulación, ejecución, supervisión y evaluación de los planes nacionales de desarrollo urbano y territorial. De este modo se da comienzo al proceso histórico del Derecho Ambiental en Uruguay, etapa que registra alcances trascendentes en materia de instrumentos con la Ley N ${ }^{\circ} 16.466$ sobre evaluación de impacto ambiental y la Ley 17.234, que crea el Sistema Nacional de Áreas Naturales Protegidas (Gorosito, 2017, p. 132).

En una etapa más avanzada del desarrollo del Derecho Ambiental, se consagran instrumentos que consolidan y reafirman la autonomía de este ordenamiento, precisamente surgen normas que explicitan los estándares formulados en el sistema regional y universal, generando un fenómeno de complementación legislativa de aquella función de fijación y formulación de las políticas que asume el Poder Ejecutivo. En este sentido, las normas de consolidación entorno a los estándares están constituidas por la Ley 17.283 — Ley de Protección del Medio Ambiente, la cual se desarrollará en las posteriores líneas dada la relevancia de su contenido - y por la Ley 17.712 de 27 octubre 2003 que aprueba el Convenio Ambiental del Mercosur y en cuyo artículo primero, se reitera y ratifica el compromiso de los Estados del Mercosur con los principios de la Declaración de Río (Santo, 2012).

En la legislación uruguaya, el puntapié inicial para que se aprobara la Ley general de protección del medio ambiente fue el artículo 47 de la Constitución. Por este motivo, se presentó ante el Parlamento un proyecto de ley que buscaba llenar el vacío legal existente en torno a este tema. A grandes rasgos, lo que se pretendía mediante esta ley era tener una normativa que declarara de interés general al medio ambiente, su protección, la 
conservación de la diversidad biológica, la prevención y mitigación de impactos ambientales negativos; y la cooperación ambiental regional e internacional.

Esta definía - tomado en cuenta las recomendaciones internacionales y regionales - lo que se consideraría desde ese momento en adelante como desarrollo sostenible y establecía los derechos y deberes de los ciudadanos en cuanto a la preservación y protección del medio ambiente. Definía también cual sería el rol del Poder Ejecutivo a través de MVOTMA (Dirección Nacional de Medio Ambiente) el encargado de coordinar la gestión ambiental y de realizar anualmente un Informe Ambiental. Además, otorgaba a las autoridades departamentales un papel importante, ya que el Ministerio podría llegar a delegar en éstas algunas tareas de gestión ambiental. Por último, es importante destacar que esta ley reservaba un espacio para disposiciones especiales que tenían que ver con la capa de ozono, cambio climático, sustancias químicas, residuos y bioseguridad.

La ley procuraba mantener la estructura jurídica de otras normas ambientales vigentes, al mismo tiempo que pretendía ser de buena calidad técnica, realista y práctica. En definitiva, se aspiraba a alcanzar un instrumento moderno de política ambiental, donde se trataba de una temática que era responsabilidad de todos preservar. De este modo, en el año 2000 entró en vigor la Ley 17.283 (Ley de Protección del Medio Ambiente), donde se observa la influencia que tiene la regulación regional del derecho al medio ambiente en la nacional, ya que durante el trámite parlamentario de la presente ley, es invocado lo establecido por los documentos del sistema interamericano de derechos humanos en materia de medio ambiente, así como también otros documentos que se han manifestado en tal sentido (Trámite Parlamentario - Ficha Asunto, Ley 17.283. Sesión:6. Parlamento del Uruguay).

Retomando con su contenido, es de interés mencionar que la presente ley en su artículo 6 señala algunos principios de política ambiental que deberá abordar el Poder Ejecutivo cuando fije la política nacional ambiental, los principios mencionados son: principio de prevención y precautorio (cuando hubiere peligro de daño grave o irreversible, no podrá alegarse la falta de certeza técnica o científica absoluta como razón para no adoptar las medidas preventivas); principio de gratuidad y progresividad de las nuevas exigencias (constituye un supuesto para la efectiva integración de la dimensión ambiental al desarrollo económico y social); principio de participación de personas y organizaciones (la protección del ambiente constituye un compromiso que atañe al 
conjunto de la sociedad); principio de transectorialidad (la gestión ambiental requiere la integración y coordinación de los distintos sectores públicos y privados involucrados); principio de adecuado manejo de la información ambiental (finalidad de asegurar su disponibilidad y accesibilidad por parte de cualquier interesado) y; principio de cooperación internacional en la materia, el cual apunta al incremento y fortalecimiento. En este punto corresponde agregar que la presente ley ha sido reglamentada en dos instancias por los decretos: N. ${ }^{\circ} 152 / 013$ y N. ${ }^{\circ} 222 / 019$.

Posteriormente, en la última reforma realizada a la Constitución uruguaya en 2004 - popularmente conocida como la Reforma del Agua - dentro del marco general de paradigma ambiental constitucionalizado, se profundiza en materia de aquellos principios que informan, imperativamente, las acciones del Estado, la sociedad y las personas. El discurso del Constituyente, expresa Gorosito (2017), parte de afirmar la relación esencial entre vida y medio ambiente, "siendo la particularización de las referencias normativas al agua y a su cuidado o salvaguarda, un instituto o garantía para la protección del medio ambiente y de la vida" (p. 130).

El artículo 47 de la Constitución le exige al Estado determinadas acciones, relativas al agua y al saneamiento, donde la política nacional en la materia tendría que estar basada en el ordenamiento del territorio, la conservación y protección del medio ambiente, la gestión sustentable de los recursos, y la participación de la sociedad civil en varias fases de la política, entre otros aspectos (Casaux, 2005). Es en función de ello que esta trajo aparejada la necesidad de sancionar nuevas leyes para poder reglamentar lo que se estableció en la Constitución, por lo que en una etapa subsiguiente, comienza un proceso expansivo del Derecho Ambiental uruguayo, ya que el texto constitucional incorpora el concepto de protección del medio ambiente al ordenamiento territorial, el cual tiene su máxima expresión con la Ley 18.308, Ley de ordenamiento territorial y desarrollo sostenible, donde se insertan, en el nivel legislativo nacional principios consagrados en las declaraciones de Estocolmo y Río, como en las declaraciones de las sucesivas Conferencias de las Naciones Unidas sobre Asentamientos Humanos.

En este mismo sentido, otros reglamentos y leyes del Uruguay son pertinentes para la protección medioambiental. Por ejemplo, las Leyes 15.239 y 18.564 reglamentan el uso y la conservación del suelo y el agua, y la Ley 13.663 (1968) rige acerca de la utilización de fertilizantes. Las empresas que se ocupan de sustancias químicas deben cumplir el Decreto 307/2009, que exige la realización de fichas de datos de seguridad que 
se ajusten a las directrices del Sistema Globalmente Armonizado de Clasificación y Etiquetado de Productos Químicos. La Ley 16.466 impone el marco normativo para las evaluaciones del impacto ambiental; requiere una previa autorización ambiental para las obras y actividades incluidas en la lista, como la construcción de carreteras, la extracción de minerales o combustibles fósiles y la explotación o la reglamentación de los recursos hídricos. La Ley 18.381 garantiza el derecho de las personas a tener acceso a la información pública sin discriminación (Sistema de Monitoreo de Recomendaciones, 2018, p. 4).

Acorde con el marco normativo nacional de protección del medio ambiente, también se ha de nombrar el acuerdo de Escazú, aprobado por la Ley N. ${ }^{\circ} 19.773$, en julio de 2019. Este ha sido impulsado por la Comisión Económica para América Latina y el Caribe, donde se subraya un claro objetivo previsto en el artículo 1 que consiste en garantizar la plena y efectiva implementación de los derechos de acceso a la información, justicia y participación pública en los asuntos ambientales, así como el fortalecimiento de las capacidades en la materia, contribuyendo de este modo a la protección del derecho a vivir en un medio ambiente sano y al desarrollo sostenible. El acuerdo es un instrumento propio de la región latinoamericana y el Caribe que materializa el Principio 10 de la Declaración de Río sobre el Medio Ambiente y el Desarrollo, teniendo en cuenta las condiciones, realidades y necesidades específicas de la región. En este sentido, se busca garantizar derechos humanos relacionados con el goce de un ambiente sano; así como también se procura garantizar un entorno propicio para el trabajo de las personas, asociaciones, organizaciones o grupos que promuevan la defensa al medio ambiente, otorgándoles reconocimiento y protección (Hernández, 2019).

Por lo anterior y en función de ello, cada Estado se compromete a mejorar y fortalecer, sus capacidades y normativa nacional. De este modo el acuerdo mencionado podría tener un importante impacto en el tema, ya que Uruguay se compromete a hacer efectivo el derecho y acceso a la información sobre ambiente contenida en los diversos instrumentos, así como también a informar de manera adecuada y accesible en materia de medio ambiente. De igual modo, Uruguay se compromete a difundir periódicamente un Informe Nacional con información sobre el estado del ambiente y los recursos. El acuerdo regula también el acceso a la justicia en asuntos ambientales, por lo cual se debe garantizar que haya órganos estatales, procedimientos efectivos, legitimación activa que 
facilite la preservación, prevención y restitución de los daños ocasionados al medio ambiente o aspectos vinculados con este.

En última instancia pero no menos importante, debe mencionarse la reciente Ley 19.829, denominada Gestión Integral de Residuos, la cual en su artículo 1 expresa que tiene por objeto la protección y promoción, del ambiente y desarrollo sostenible, en concordancia con lo establecido en la Ley $\mathrm{N}^{\circ}$ 17.283, del año 2000, mediante la prevención y reducción de los impactos negativos; así como también la creación del Ministerio de medio ambiente, con competencias exclusivas en materia medioambiental, el cual fue creado por el artículo 291 de la Ley $N{ }^{\circ} 19.889$, de 9 de julio de 2020. En función de ello, las competencias ambientales asignadas a MVOTMA —el ministerio encargado desde 1990 hasta la fecha de las cuestiones ambientales - fueron transferidas al Ministerio de Ambiente por la ley que lo creó.

Tras el abordaje de la protección jurídica del derecho al medio ambiente en el sistema nacional es posible destacar el interés instaurado en torno al mismo mediante su transición histórica, por lo cual ha evolucionado notoriamente.

\section{Desafíos del derecho al medio ambiente en el sistema jurídico uruguayo}

En apartados anteriores fue analizada la evolución en materia de regulación jurídica del derecho al medio ambiente en el sistema regional y nacional, observándose la influencia del sistema regional en el nacional. Ahora me referiré a algunos de los desafíos que ha presentado tal derecho en el Uruguay en los últimos años, donde, en rasgos generales, es posible expresar que muchos de los problemas no han tenido respuesta o no se han efectivizado pese a la regulación jurídica.

Debe señalarse que distintos instrumentos y países expresan que Uruguay tiene muchas buenas prácticas en relación con los derechos humanos y el medio ambiente, lo que refleja un compromiso general de respetar y proteger los derechos humanos en sus políticas ambientales, observándose un progreso importante en materia de desarrollo sostenible mediante políticas como la de transformación energética y la ejecución de planes de ordenación y aprovechamiento de tierra. Además, tras la observación de distintos trámites parlamentarios que llevaron a las leyes que regulan la protección jurídica del derecho al medio ambiente en Uruguay, como lo es la Ley 17.283, es posible constatar cómo han influido los documentos jurídicos que regulan el derecho al medio 
ambiente en el sistema regional, ya que son invocados como disposiciones introductorias y argumentos a fin de resaltar la relevancia que tiene la protección medioambiental.

Sin embargo, al igual que otros países, Uruguay se enfrenta a problemas en el cumplimiento de las obligaciones de derechos humanos relacionadas con el medio ambiente. Por lo que a continuación se recogen varios de los problemas que señalaron muchos relatores especiales — miembros del sistema internacional — durante la visita. (Sistema de Monitoreo de Recomendaciones, 2018, p. 7) .

Un aspecto fundamental de la protección de los derechos humanos en el contexto ambiental es la aplicación del derecho a la información sobre los problemas y las políticas ambientales. Sobre esta línea, Uruguay mediante la Ley 17.283 principalmente, ha reconocido que el acceso a la información ambiental es necesario para proteger los derechos humanos frente a su violación por daños ambientales. En este sentido, en Uruguay se encuentra la Ley $\quad$ N. ${ }^{\circ} 8.381$ sobre el derecho de acceso a la información pública; sin embargo, desde los informes de relatores especiales se acoge el hecho de que, sobre diversos aspectos del sistema de información sobre el medio ambiente, algunos observadores han señalado la falta de suficientes investigaciones sobre los nexos entre los problemas ambientales y los problemas de salud.

Además, algunos representantes de la sociedad civil han observado que el acceso a la información no siempre es efectivo, por varias razones, entre ellas que los documentos pertinentes pueden ser demasiado técnicos para resultar de fácil comprensión, y que a menudo son difíciles de encontrar. Otra de las problemáticas relacionadas con el acceso a la información es que muchas veces resulta difícil determinar qué organismo es el responsable de proporcionar la información solicitada. Para evitar estas consecuencias se requieren medidas institucionales, donde la consigna debe ser la incorporación de estas nuevas informaciones y datos para mejorar los resultados. De ello se deduce la justificación y función de la política ambiental.

En lo que respecta a la protección jurídica del derecho al medio ambiente, es relevante señalar la tensión existente entre protección ambiental y desarrollo económico, lo cual es solucionado por la vía del desarrollo sostenible, en este sentido se ha expresado que a fin de alcanzarlo, la protección del medio ambiente deberá constituir parte integrante del proceso de desarrollo y no podrá considerarse en forma aislada. Así pues, el principio del desarrollo sostenible supone una armonización entre el progreso social y 
económico y la protección ambiental, es decir que se sintetiza el crecimiento económico y la preocupación por el medio ambiente como dos caras de la misma moneda.

Un crecimiento económico ilimitado y a costa de la depredación de los bienes ambientales, hipoteca las posibilidades de crecimiento, e incluso de supervivencia, en el futuro. Por el contrario, en el caso hipotético de una protección ambiental irrestricta, se hipotecará el bienestar y la calidad de vida de las personas presentes. Sobre estas líneas corresponde señalar entonces, que el desarrollo sustentable supone una utilización racional de los recursos, por lo que debe considerarse que la protección y conservación del medio ambiente se trata de ponderar los costos y beneficios. En la práctica, resulta muy difícil llevar adelante una política de medio ambiente eficiente, sobre todo porque su beneficio es muy difícil de medir y de cuantificar. Por lo tanto, la política ambiental suele limitarse a objetivos menos ambiciosos, tal como la minimización de los costos.

Acerca del principio de participación de personas y organizaciones en materia de medio ambiente consagrado en la Ley 17.283 tras la visita del Relator especial en 2018, las organizaciones de la sociedad civil manifestaron su preocupación por el hecho de que el plazo previsto por las autoridades no era suficiente para realizar un análisis exhaustivo de los efectos que el proyecto podría tener sobre el medio ambiente. También, se quejaron de que, pese a los esfuerzos por resaltar los efectos adversos en el medio ambiente en la audiencia pública de septiembre de 2016, no se recibió respuesta del Gobierno; por consiguiente, las comisiones no parecen funcionar de manera eficiente en lo que refiere al principio de participación (Sistema de Monitoreo de Recomendaciones, 2018).

En estas líneas dichos relatores han señalado además que, dado a que los Estados deben facilitar el acceso a recursos eficaces ante las violaciones de derechos humanos así como también a leyes nacionales relativas al medio ambiente, motivo por el cual en Uruguay existen mecanismos tendientes a ofrecer tales recursos; en la práctica no siempre se da como debería, esto surge del hecho de que el relator especial recibió varias quejas sobre dichos recursos donde se ha alegado que estos son confusos. En términos más generales, el relator también escuchó las preocupaciones sobre el cumplimiento de las leyes ambientales a nivel judicial. Los mecanismos de denuncia administrativos a menudo no son suficientes por sí solos para garantizar el cumplimiento de las leyes ambientales. Lo que hace necesario prever el acceso efectivo a los tribunales, y en este sentido se ha expresado que es fundamental que el propio Gobierno cumpla sus responsabilidades para 
hacer aplicar las leyes ambientales mediante la adopción de medidas coercitivas en los casos pertinentes.

Por otra parte, pero relacionado a ello, como bien se señaló en los apartados anteriores, Uruguay en el año 1997 introdujo el art. 47 a la Carta, el cual establece que la "protección del medio ambiente es de interés general", por lo que las personas deben abstenerse de cualquier tipo de acto que cause depredación, destrucción o contaminación grave al medio ambiente. A modo de crítica, surge que el art. 47 al emplear el término "grave" al momento de sugerir a lo que las personas deben abstenerse, nada dice sobre que es grave, en materia de medio ambiente, así como un gran incendio puede considerarse grave, también podría ser una gota de un líquido especial al verterse en un río, por ejemplo. Con relación a esto debe señalarse que la mayoría de los daños al medio ambiente producen efectos en cadena, por lo cual resulta bastante complejo entender a que refiere el término "grave" empleado en tal artículo.

En lo que respecta a la jurisprudencia uruguaya en materia de medio ambiente, tras un análisis general en la base de jurisprudencia, es posible observar aunque en forma escasa, la invocación del art. 11 del Protocolo a la Convención en conjunto con el art. 47 de la Constitución uruguaya y otras normas de carácter infra constitucional en materia de medio ambiente; por lo que visualizamos la influencia que tiene el sistema regional en el sistema nacional uruguayo a fin de lograr una protección al derecho mencionado.

Algunos ejemplos de lo mencionado son las sentencias nro.35/2007 (Tribunal Apelaciones Civil $3^{\circ} \mathrm{T}^{\mathrm{o}}$. Sentencia nro.35/2007, 2007); nro. 1/2016 ( Juzgado Ldo.Civil $4^{\mathrm{o}} \mathrm{T}^{\mathrm{o}}$. Sentencia nro.1/2016, 2016) y; nro.71/2017 (Tribunal Apelaciones Civil $7^{\circ} \mathrm{T}^{\mathrm{o}}$. Sentencia nro.71/2017, 2017). Pese a ello, se empleó el vocablo de forma escasa ya que, de lo observado, hasta el momento no se han dado muchas sentencias que refieren a temáticas medio ambientales en comparación con otras áreas, y en varios casos donde se ha tratado el derecho al medio ambiente, muchas veces no suele citarse el Protocolo de San Salvador como marco jurídico aplicable que contiene tal derecho o la jurisprudencia emitida por el SIDH, lo cual podría ser calificado como un desafío actual en materia de medio ambiente. Como respuesta a tal desafío se deberían de fortalecer las instituciones y jurisprudencia, de manera que las instituciones judiciales sean modernas, eficaces y capaces, a fin de promover el desarrollo del derecho al medio ambiente a través de la jurisprudencia. 


\section{Conclusión}

A la luz de lo expuesto se concluye, en primera instancia, el vertiginoso desarrollo que ha tenido la regulación jurídica del derecho al medio ambiente en los últimos años dentro de los sistemas mencionados en donde se desprenden cuestiones de multifuncionalidad.

Por lo anterior, y respecto al primer objetivo de este artículo, es posible visualizar el efecto del diálogo de las fuentes del derecho, ya que todo señala que la percepción que ha realizado el sistema regional de derechos humanos en lo que respecta al derecho al medio ambiente ha servido de base para la protección por parte del ordenamiento jurídico interno, constituyendo, de este modo, además de un hincapié para su respectiva protección, un complemento y apoyo al derecho interno.

Así, es menester señalar que los estándares y principios desarrollados por los órganos regionales mediante sus distintas funciones -los cuales versan principalmente en respetar, garantizar y prevenir daños ambientales- no sólo han permitido la solución de casos a nivel regional, sino que constituyen directrices interpretativas tendientes a proporcionar un incentivo a los Estados Partes de la Convención, como lo es Uruguay sobre la adopción de actitudes jurídicas más eficaces para la protección del medio ambiente y de los derechos humanos.

Para finalizar, en lo limitado del presente análisis, respecto al segundo objetivo, se concluye también que pese al amplio respaldo jurídico que posee el ordenamiento interno en materia medioambiental este aún no ha sido aplicado de forma significativa en la realidad, lo cual es posible constatar mediante la jurisprudencia uruguaya observada y los informes realizados por los Relatores Especiales. Ello significa un desafío en múltiples aspectos, lo que en definitiva hace a la efectividad material de tal derecho en el ordenamiento uruguayo. No obstante, es relevante destacar cómo el sistema jurídico uruguayo tiene la intención de proteger este derecho, desencadenando una concentración de esfuerzos que ha aumentado notoriamente en los últimos años. 


\section{Referencias}

Blengio, M. (2012). Derecho a un medio ambiente sano. Revista de Derecho de la Universidad de Montevideo, 2(4), 5-18. Recuperado de http://revistaderecho.um.edu.uy/wpcontent/uploads/2012/12/Blengio-Derecho-humano-a-un-medio-ambiente-sano.pdf

Calderón Gamboa, J. (2017). Medio ambiente frente a la Corte Interamericana de Derechos Humanos: una ventana de protección. Recuperado de https://biblioteca.corteidh.or.cr/documento/72042

Carta Social de las Américas. (4 de junio de 2012). Recuperado de http://www.derechoshumanos.unlp.edu.ar/buscador/search/instrumento/33

Casaux, G. (2005). Derecho ambiental: legislación nacional e internacional sobre calidad de aguas. Revista de la Facultad de Derecho, (15), 121-138. Recuperado de https://revista.fder.edu.uy/index.php/rfd/article/view/336

Cerqueira, D. (2020). El derecho a un medio ambiente sano. Recuperado de http://www.dplf.org/sites/default/files/el_derecho_a_un_medio_ambiente_sano.pdf

Comisión Interamericana de Derechos Humanos. (2015) Pueblos indígenas, comunidades afrodescendientes y recursos naturales: protección de derechos humanos en el contexto de actividades de extracción, explotación y desarrollo. Recuperado de http://www.oas.org/es/cidh/informes/pdfs/IndustriasExtractivas2016.pdf

Comisión Interamericana de Derechos Humanos. (2019a). Situación de los derechos humanos de los pueblos indígenas y tribales de la Panamazonía. Recuperado de http://www.oas.org/es/cidh/informes/pdfs/Panamazonia2019.pdf

Comisión Interamericana de Derechos Humanos. (2019b). Informe Empresas y Derechos Humanos: Estándares Interamericanos. Recuperado de http://www.oas.org/es/cidh/informes/pdfs/EmpresasDDHH.pdf

Comisión Mundial de Áreas Protegidas y WWF Internacional. (2001). Pueblos Indígenas y Tradicionales y Áreas Protegidas. Principios, Directrices y Casos de Estudio. Recuperado de https://www.iucn.org/downloads/pag_004_es.pdf.

De Olivera Mazzuoli, V y De Faria Moreira, G. (2015). Protección jurídica del medio ambiente en la jurisprudencia de la corte interamericana de derechos humanos. Revista de Derecho de la Universidad de Montevideo, 28(7), 41-61. Recuperado de http://revistaderecho.um.edu.uy/wp-content/uploads/2016/03/DE-OLIVEIRAMAZZUOLI-Valerio-y-DE-FARIA-MOREIRA-Gustavo-Proteccion-juridica-delmedio-ambiente-en-la-jurisprudencia-de-la-Corte-Interamericana-de-DerechosHumanos.pdf

Gorosito, R. (2017) Los principios del derecho ambiental. Revista de Derecho, 13(16), 101-136. https://doi.org/10.22235/rd.v2i16.1471

Hernández, S. (2019). Los nuevos derechos de acceso en matéria ambiental: el caso del Acuerdo de Escazú. Estudios en Derecho a la Información, 9. Recuperado de https://revistas.juridicas.unam.mx/index.php/derechoinformacion/article/view/14281/15529 
Iglesias, G. (2020) La protección del ambiente en la Constitución de la Republica. Revista de Derecho Público, 29(57), 139-157. Recuperado de http://www.revistaderechopublico.com.uy/ojs/index.php/Rdp/article/view/139/107

Ley $\mathrm{N}^{\circ}$ 17283, Ley de Protección del Medio Ambiente. (2000, 12 de diciembre). Centro de Información Oficial. Recuperado de https://www.impo.com.uy/bases/leyes/17283-2000

Risso, M. (2005). Derecho Constitucional. Tomo 1. Montevideo, Uruguay: Fundación de Cultura Universitaria.

Santo, N. (2008). Los principios generales del derecho ambiental y la industrialización. Revista de Derecho de la Universidad de Montevideo, 7(14), 179-186. Recuperado de http://revistaderecho.um.edu.uy/wp-content/uploads/2012/10/DERECHO-14.pdf

Secretaría del Convenio sobre la Diversidad Biológica. (2004). Principios y Directrices de Addis Abeba para la Utilización Sostenible de la Diversidad Biológica (Directrices del $C D B$ ). Recuperado de https://www.cbd.int/doc/publications/addis-gdl-es.pdf.

Sistema de Monitoreo de Recomendaciones. (2018). Informe Relator Medio Ambiente y DDHH. Recuperado de https://simore.mrree.gub.uy/Adjuntos/Informe\%20Relator\%20Medio\%20Ambiente\%20 y\%20DDHH_2018.pdf

Valla, M. F. (2016) Evolución de la institucionalidad ambiental en el Uruguay 1990 - 2015. (Tesis de grado). Universidad de la República, Montevideo, Uruguay. Recuperado de https://www.colibri.udelar.edu.uy/jspui/bitstream/20.500.12008/8893/1/TCP_VallaFlor encia.pdf

WWF Internacional (2008). Los Pueblos Indígenas y La Conservación: Declaración de Principios del WWF. Recuperado de http://awsassets.panda.org/downloads/183113_wwf_policyrpt_sp_f_1.pdf

\section{Jurisprudencia y normativa legal consultada}

Corte Interamericana de Derechos Humanos. Caso Claude Reyes y otros Vs. Chile. 2006.

Corte Interamericana de Derechos Humanos. Caso de la Comunidad Moiwana Vs. Suriname. 2005.

Corte Interamericana de Derechos Humanos. Caso Comunidad Indígena Yakye Axa vs. Paraguay. 2005.

Corte Interamericana de Derechos Humanos. Caso Comunidad Indígena Xákmok Kásek vs. Paraguay. 2010.

Corte Interamericana de Derechos Humanos. Caso Pueblo Saramaka Vs. Surinam. 2008.

Corte Interamericana de Derechos Humanos. Caso Comunidad Indígena Sawhoyamaxa vs. Paraguay. 2006.

Corte Interamericana de Derechos Humanos. Caso Comunidad indígena Yakye Axa Vs. Paraguay. 2006. 
Corte Interamericana de Derechos Humanos. Caso Comunidades indígenas miembros de la Asociación Lhaka Honhat (Nuestra. Tierra) Vs. Argentina. 2020

Corte Interamericana de Derechos Humanos. Caso Pueblos Kaliña Y Lokono vs. Surinam. 2015.

Corte Interamericana de Derechos Humanos. Caso Pueblo indígena Kichwa de Sarayaku vs. Ecuador. 2012.

Corte Interamericana de Derechos Humanos. 2017. Opinión Consultiva OC-23/17

Juzgado Ldo.Civil $4^{\circ} \mathrm{T}^{\mathrm{o}}$. (2016, 1 de febrero). Sentencia nro.1/2016. Disponible en BJN Pública. Accedido 18 de octubre 2020 desde

http://bjn.poderjudicial.gub.uy/BJNPUBLICA/busquedaSelectiva.seam?cid=440137.

Trámite Parlamentario - Ficha Asunto, Ley 17.283. Sesion:6. Parlamento del Uruguay.

Accedido 20 de septiembre 2020, desde parlamento.gub.uy

Tribunal Apelaciones Civil $3^{\circ} \mathrm{T}^{\circ}$. (2007, 26 de febrero) Sentencia nro.35/2007. Disponible en BJN Pública. Accedido 18 de octubre 2020 desde http://bjn.poderjudicial.gub.uy/BJNPUBLICA/busquedaSelectiva.seam?cid=440137.

Tribunal Apelaciones Civil $7^{\circ} \mathrm{T}^{\mathrm{o}}$. (2017, 5 de junio) Sentencia nro.71/2017. Disponible en BJN Pública. Accedido 7 de noviembre 2020 desde http://bjn.poderjudicial.gub.uy/BJNPUBLICA/busquedaSelectiva.seam?cid=440137.

\section{Contribución autoral}

a) Concepción y diseño del trabajo; b) Adquisición de datos; c) Análisis e interpretación de datos; d) Redacción del manuscrito; e) revisión crítica del manuscrito.

M. B. P. ha contribuido en a, b, c, d, e.

Editor científico responsable: Dra. María Paula Garat. 